\title{
Problem-Based Learning for the Teaching of Skills: Results of a Practical Use
}

\author{
Alexander Redlein \\ TU Wien, IFM \\ Christian Lau \\ TU Wien, IFM
}

Digitalisation and COVID-19 have been changing the way we teach. Last year distance learning was often the only possibility to transfer knowledge. Based on an intensive literature review, the paper presents best practices to enable knowledge transfer and analyses the possibilities and shortcomings of two approaches by applying them in several case studies:

1) Blended learning: provides content and knowledge mainly with the help of learning videos and feedback/reflection sessions.

2) Problem-based learning: secures that the students can apply the learned content and methodologies.

Beside the results of the case studies the paper provides the feedback of the students.

Keywords: problem based learning, advanced blended learning, practical use, case study, ERP teaching

\section{BACKGROUND AND OBJECTIVES}

Digitisation has already changed the way in which competences are taught at secondary and tertiary level in recent years. Nevertheless, the focus was on face to face events for the transfer of knowledge and competence. The use of digital techniques and media has been researched and tested, but has not been implemented widely. COVID-19 has also not really been a "game changer" for the last year, but it has made the use of e-learning and blended learning almost a must. Since March last year, most universities in Austria and many countries have had almost no classroom teaching. Within a very short time, courses were adapted from physical to virtual teaching. A lot of universities state they now make most of their offerings available digitally. In most cases, however, only digital tools for video conferencing were used instead of the physical classroom to convey the content. This means that instead of in the classroom or seminar room, the content was conveyed via Zoom or other videoconferencing software. This article deals with more advanced methods such as blended learning and problem-based learning.

\section{LITERATURE REVIEW AND METHODOLOGY}

According to literature, there is a variety of teaching methods. Every year, the "mmb Institut für Medien- und Kompetenzforschung" (Department for Media and Competence Research) publishes an 
overview of the status quo of digital teaching concepts and their use. The mmb differentiates between to formal and informal as well as individual and collaborative methods.

Individual methods focus on the transfer of knowledge for a single individual. Collaborative methods mainly use social cooperation e.g. team settings. (mmb Institut, 2019)

Informal learning encompasses all learning processes that take place without direct intent to learn. This is done, for example, through participation in forums and social networks, but also through work itself or through exchanges with colleagues. Formal learning, on the other hand, encompasses all ways of learning that provide knowledge in a planned manner. Examples are webinars, blended learning, courses, lectures and seminars (de Witt, 2012). Figure 1 shows the main current teaching methods depending on these two classifications (mmb Institute, 2019).

\section{FIGURE 1 \\ LEARNING METHODS ACCORDING TO MMB INSTITUT 2019}

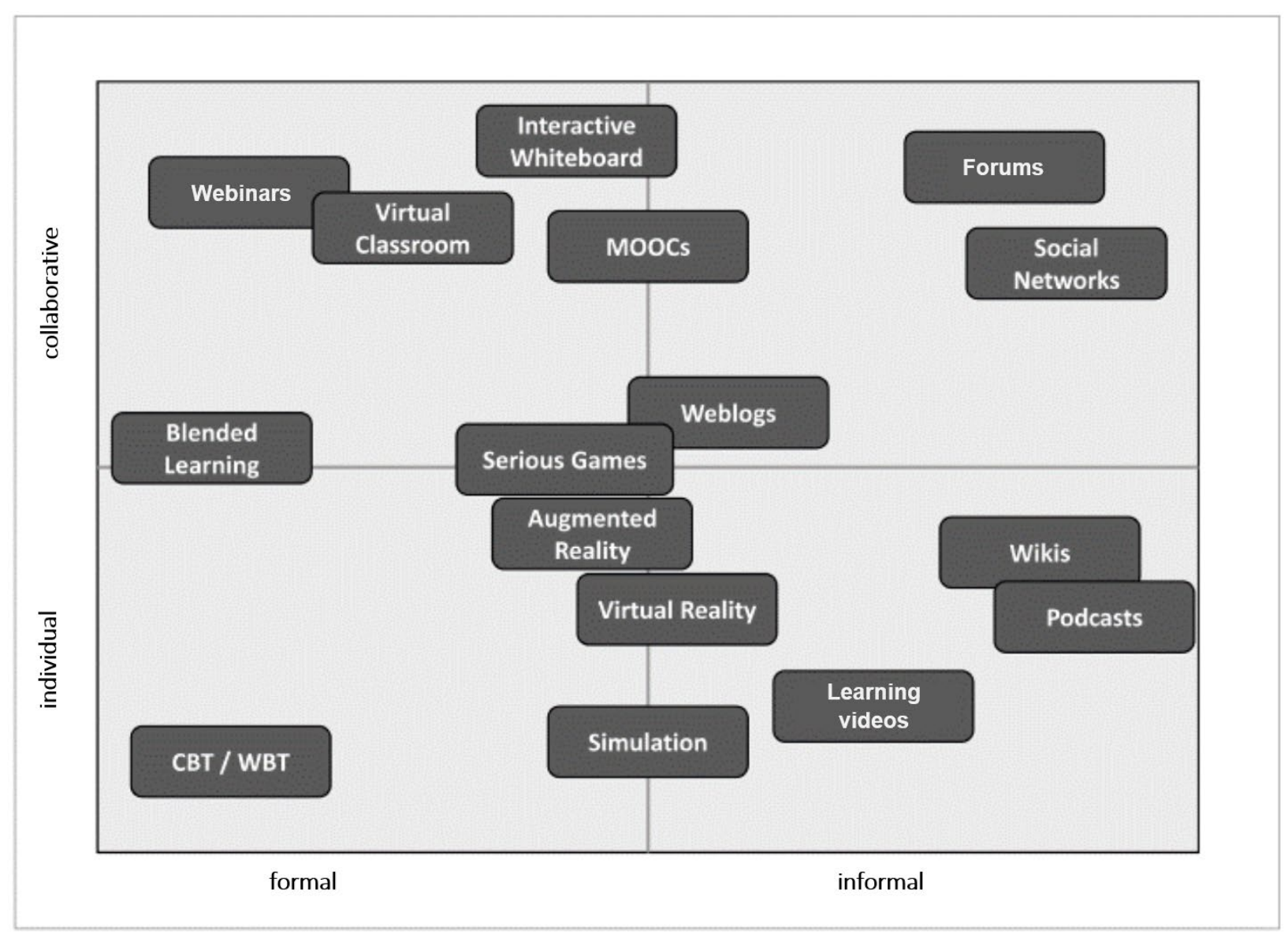

Another classification can be found at Nele Graf et.al. 
TABLE 1

LEARNING METHODS ACCORDING TO NELE GRAF ET.AL. 2019

\begin{tabular}{|l|l|l|l|}
\hline & Dimension & Traditional learning & Agile learning \\
\hline 1 & Initiative & Company & Employee \\
\hline 2 & Trigger & Learning for supply & Learning on demand \\
\hline 3 & Relation to work & Off the job & On the job \\
\hline 4 & Goal of learning & Knowledge & Competence \\
\hline 5 & Certificate & Formal & Informal \\
\hline 6 & Degree of freedom & Externally controlled & Internally controlled \\
\hline 7 & IT support & Mostly analogue & Mostly digital \\
\hline 8 & Communication & Synchronic & Asynchronic \\
\hline 10 & Collaboration & Individual & Team-oriented \\
\hline 11 & Learning taxonomy & To know and understand & To analyse and evaluate \\
\hline
\end{tabular}

These two examples are intended to illustrate only how many opportunities, developments and trends there are in the field of learning and skills acquisition. Despite this diversity, however, most teachers still prefer formats based on face to face events, i.e. physical presence (mmb Institut, 2019, Siepmann, 2018, Poxleitner, 2018, Redlein, et.al., 2021). These are, for example, lectures with attendance or workshops and seminars (mmb Institut, 2019, Siepmann, 2018, Poxleitner, 2018). This is mainly due to the fact that in this way the interaction and motivation of the learners can be ensured easily (Gutbrod, 2020, p. 48). Also, the feedback from the participants can be collected the easiest. Pure passive, digital learning methods such as learning videos have major weaknesses here (Modlinger, 2020, p. 166, Kerres, 2018, p. 118).

As mentioned in Redlein, et.al., 2021., a middle way are the so-called blended learning formats, in which different methods and media (face to face, readings, learning videos, etc.) are combined (Kerres, 2018, p. 23, Erpenbeck, et.Al., 2015, p. 29, Gabler, 2021, Bender, 2021). For example, classroom teaching is mixed with e-learning formats to ensure interaction, motivation and, above all, to guarantee the acquisition of competence (Kraft 2003, p. 45). Presence formats and self-learning phases alternate. The presence phases ensure interaction, the possibility to eliminate ambiguities, ask questions and provide feedback. E-learning enables flexible time design (Erpenbeck, et.al., 2015, Feldmann \& Wolff, 2018, p. 200, Redlein, et.al. 2021). The possibility to select the relevant content yourself, if necessary to view content several times, supports individuality and flexibility (Bremer, 2017).

The location independence that comes with e-learnings that can be accessed whenever and wherever, are an advantage here (Stock-Homburg \& Groß, 2019, Erpenbeck, et.al., 2015). The tools in the field of elearning are diverse. The simplest are digital papers or videos. But also animations, simulations, virtual and augmented reality technologies and gamification are to be mentioned here (Behrend \& Gandomi, 2019). So far, these advanced methods have only been used in more specific, especially potentially risky scenarios (Arnold, et.al., 2018). These advantages are also mentioned by Redlein, et.al., 2021. However, the challenges of the past year have also increased the usage of these approaches in higher education.

In this paper, two approaches are used in practice to analyse the pros and cons of the methods.

1) Blended learning based on the Springer iversity platform: In order to promote international knowledge about FM, an introductory course for FM was designed and implemented jointly by the IFM of the TU Wien and Springer. For this purpose, the procedure model of Springer iversity was used to ensure interaction and knowledge transfer. The procedure model gives input on designing the learning videos with respect to Kerres, 2018. The experience and the procedure model were then used in the conversion of further lectures into hybrid formats at several courses of various universities. 
2) Problem-based learning: Stanford University conducts the design thinking training ME310 as a problem-based learning course. This is done in partnership with other universities and industry partners. One of the partner universities is the IFM of the TU Wien. In the second use case, the problem-based learning method and the experience of the ME310 course design was used to teach the students of the TU Wien competences in the field of process management and IT support within FM.

\section{RESULTS}

\section{Blended Learning Based on the Springer iversity Platform}

The experience and specifications of Springer iversity led to a serious redesign of the lecture and the lecture documents. The cover page of the iversity course is shown in figure 2 .

FIGURE 2

SPRINGER COURSE COVER PAGE "INTRODUCTION TO FM"

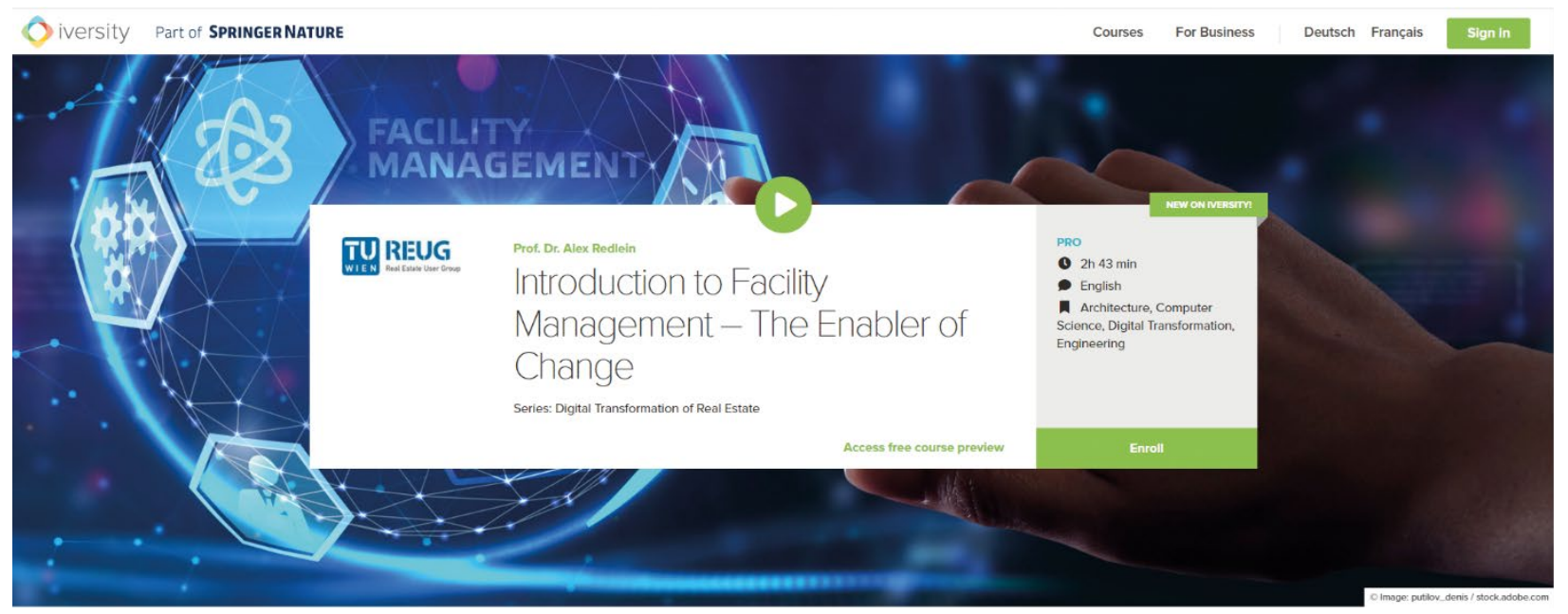

The lecture is now structured in the following way (comp. figure 3) (Redlein, et.al., 2021):

1) In the Kick-off session the competences gained, learning methods used and schedule, tasks/submission of students and teaching staff, etc. are presented. This kick-off is a face to face session or held via ZOOM.

2) Self-learning unit about micro- and macro-economic impact.

3) Feedback session to answer questions, for a critical review of the learning videos and to show relationships between the micro- and macro-economic impact of FM, the number of employees working in this sector and the "value added" generated by them. This session is again a face to face unit or held via ZOOM.

4) Self-learning unit about the different definitions.

5) Feedback session to answer questions, for a critical review of the learning videos and to show relationships between the definitions of EuroFM, IFMA, ISO and EN. This session is a face to face unit or held via ZOOM.

6) Self-learning unit about the practical application of the definitions.

7) Feedback session to answer questions for a critical review of the learning videos and to make a deep dive into the possibilities of the application of the EN15221-1 Appendix A model to implement FM in a company. This session is a face to face unit or held via ZOOM. It also sums up the whole content. 


\section{FIGURE 3 \\ CONTENT OF SPRINGER COURSE AND DETAILS OF A CHAPTER}

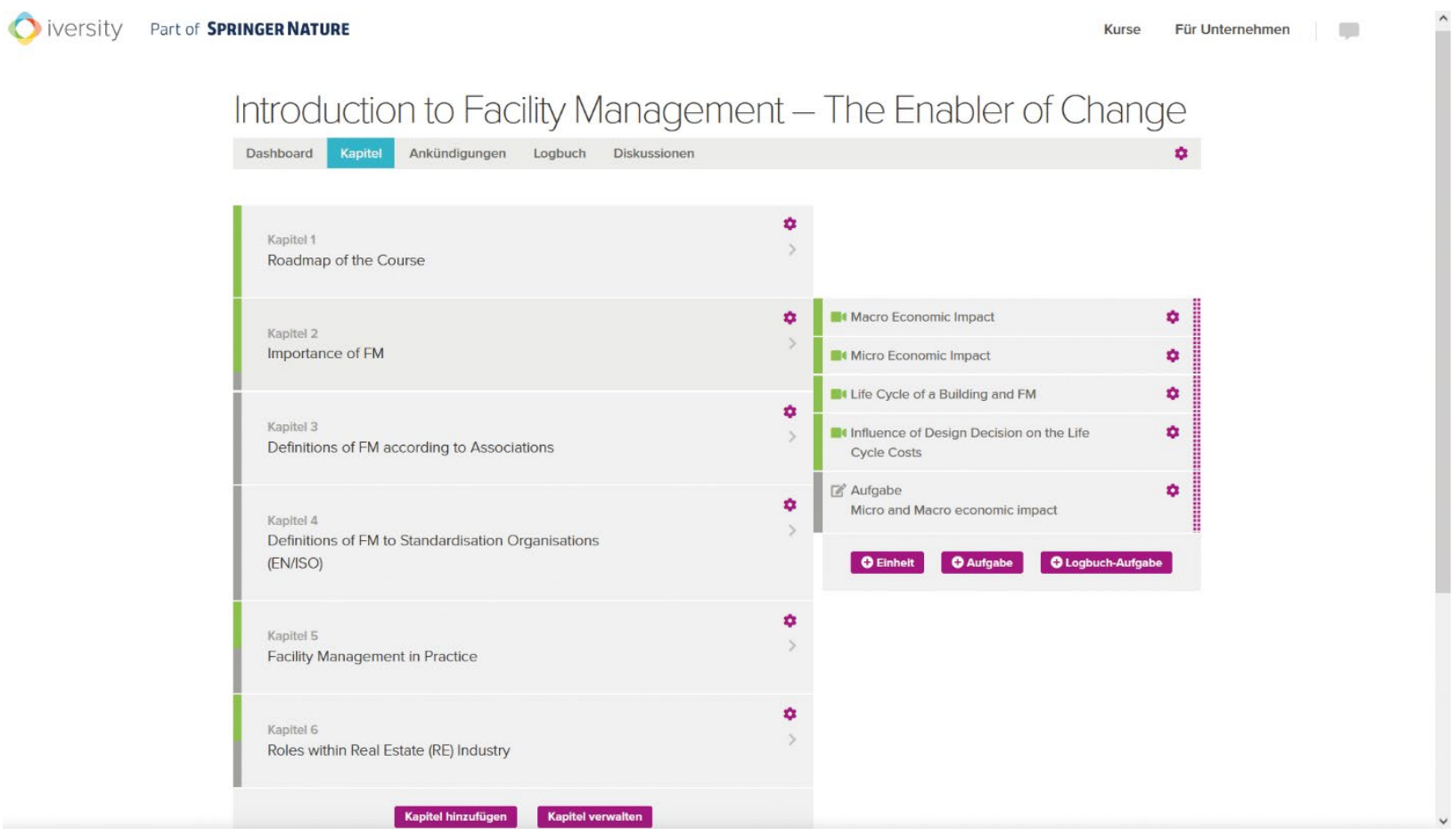

The same concept is now also used for the lecture "Introduction into FM" at TU Wien. Also in this lecture the self-learning and the feedback sessions alternate. Based on the feedback of the students the time frame of feedback sessions were enlarged and their number was increased.

The advantage of this project was that a textbook "Modern Facility and Workplace Management" (Redlein, et.al., 2020) was published by Springer Verlag in spring 2020. This was used as pre-reading, as a consolidation and deep dive into the topic. The learning content was divided into 5-minute units. In this way, the concentration and communication of the content can be optimised. However, this is by no means in line with the classical transfer of knowledge at universities and colleges, which is always structured in 45-minute units. Therefore, the lecture has been revised completely in this regard.

Storytelling, the teaching of the content based on practical examples, was also included in the videos. Theoretical content is presented not only through the definition, but also using an example from a company (Kerres, 2018, p. 161). The creation of the learning videos themselves also turned out to be complex. One can assume that one hour of learning videos in total means two to three days of effort.

According to Redlein, et.al., 2021 the time intensive tasks are the conversion of the content to 5-minute units, the setting for the video recording (background, lighting, utensils, etc.), the filming, but also the postprocessing of the videos and above all the partially repeated cuttings and editing (Kerres, 2018, p. 473-475, Modlinger, 2020, p. 99-100, Modlinger, 2020, p. 122-130). All these tasks are very time consuming. Only if the material can be used several times the conversion pays off. Figure 4 shows an example how the content is linked to the videos. They are grouped according to the chapters in playlists, so that the students can watch the relevant ones easily until the next feedback session in order to learn the content and gain the new competences. 
FIGURE 4

SCREENSHOT OF LECTURE 'INTRODUCTION INTO FM' TU WIEN PLAYLIST VIDEOS

\section{TU IIIM

Beispiel FM TU: Abschnitte

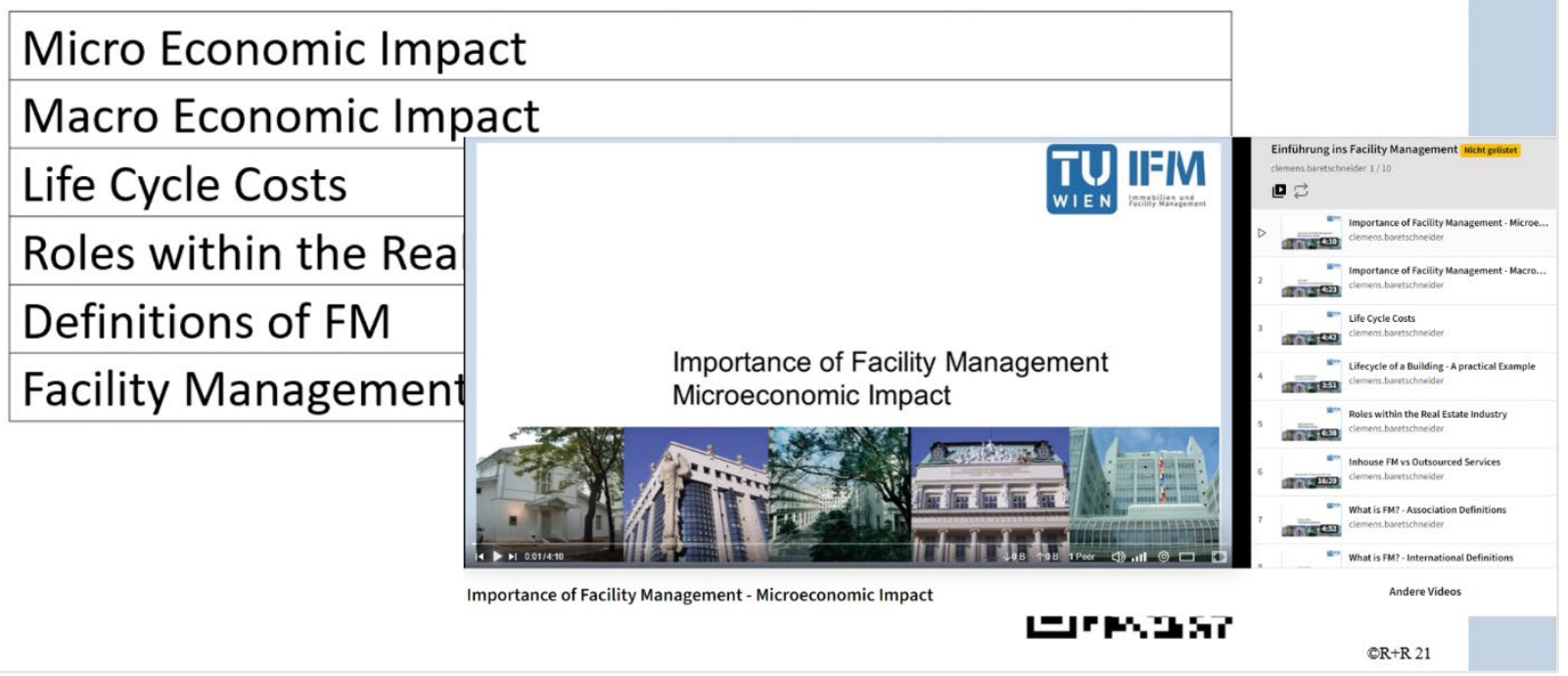

Especially the tutorials of Springer iversity have given good support and guidance here. They are much more detailed than the usual manuals at universities, and therefore support the work much more comprehensively and ensure a higher quality (Springer, 2021). By using quiz formats, learners can also independently control their learning progress (Kerres, 2018).

This method and approach have also been used by the IFM's teaching team when having adapted five lectures at three universities. The feedback from the students from all five case studies was very good. Storytelling, in particular, is perceived as important because it establishes a connection to practice. The possibility of acquiring knowledge flexibly and regardless of location is also considered positive (Erpenbeck, et.al., 2015). However, the opportunity to receive sufficient personal feedback must remain in order to ensure long-term satisfaction and learning success.

\section{Problem-Based Learning}

The second approach is based on the experiences of creating blended learning courses, but incorporates the approach of problem-based learning. In this case, the learner should primarily use her/his acquired skills to solve a real problem of practice. This proves whether only knowledge or also the competence to apply the knowledge has been acquired. In a first step the students learn how to model processes based on the example of the 'failure handling process'. The first learning videos end with a submission order to the students. The next video starts with an example solution and the common shortcomings. Then the next step is described and another submission is requested. This process consists of six steps. In this way the students learn how to model and optimise processes. At the end of the last learning video, the students get another submission. They have to apply the methodology learned to optimise the "preventive maintenance" process. (Kerres 2018, p. 363 - 370, Weber, 2005)

This approach is more likely to be used in small groups, as the learners usually acquire the knowledge in self-study and the teachers act primarily as coaches. Therefore, this method is very laborious for the teachers. Short response times and personal support are very important for the learning success and 
satisfaction of the learners (Weber, 2007). At TU Wien, however, this method was used in a seminar with around 50 students.

Experience shows that Europeans including students of an Austrian university have to familiarize themselves with the method first. The first feedback was from "You dare to do something" to "Super". The feedback from the students confirms, that they accept the method well and are enthusiastic about the flexibility of the learning method. There was actually no negative feedback. The analysis of the grading of the first two courses shows that the grading was analogous to the last semesters. There was even a slight tendency towards better grades, but this cannot yet be considered statistically relevant.

Again, it should be noted that the teaching team has spent much time on feedback to ensure short response times. In addition to synchronous feedback methods such as Zoom meetings, asynchronous methods such as e-mail or even a ticket system were used. All these feedback tools were also extensively used by the students.

\section{CONCLUSION}

Overall, based on the case studies conducted, it can be said that blended learning and problem-based learning can be used well in hybrid or even purely virtual teaching. A mix between digital types of content mediation and personal feedback must be used. The cost of this changeover is considerable, but pays off. The results of the case studies show that student satisfaction and learning outcomes in terms of grading are very high.

However, it cannot be assumed that the number of lectures and tutors can be saved, as rapid response times to questions and feedback rounds in sufficient numbers are important for success. The IFM is currently working to test these methods for their suitability also in the field of secondary education, especially in the area of upper secondary education. The initial results show that feedback loops and teacher availability are even more important for success.

\section{REFERENCES}

Arnold, P., Kilian, L., Thillosen, A., \& Zimmer, G. (2018). Handbuch E-Learning (5th Edition). Bielefeld: Bertelsmann Verlag.

Behrend, R., \& Gandomi, S. (2019). Berufliche Weiterbildung im Zeitalter der Digitalen Transformation. Leitfaden für Weiterbildungsanbieter 2019. Frankfurt am Main: Weiterbildung Hessen e. V.

Bendel, O. (2021). Blended Learning. Gabler Wirtschaftslexikon. Retrieved June 29, 2021, from https://wirtschaftslexikon.gabler.de/definition/blended-learning-53492/version-384383

Bremer, C. (2017). Einsatz digitaler Medien in der Hochschullehre: Szenarien und Mehrwerte für die Kometenzentwicklung. In J. Erpenbeck \& W. Sauter (Eds.), Handbuch Kompetenzentwicklung im Netz, Bausteine einer neuen Bildungswelt (pp. 307-336). Stuttgart: Schäfer-Pöschel.

de Witt, C. (2012). Neue Lernformen für die berufliche Bildung: Mobile Learning - Social Learning Gamed Based Learning. Bundesinstitut für Berufsbildung. Wiesbaden: Springer VS.

Erpenbeck, J., Sauter, S., \& Sauter, W. (2015). E-Learning und Blended Learning, Selbstgesteuerte Lernprozesse zum Wissensaufbau und zur Qualifizierung. Wiesbaden: Springer VS.

Feldmann, J., \& Wolff, D. (2018). Hochschule 4.0 "If we teach today's students as we taught yesterday's, we rob them of tomorrow." (John Dewey). In D. Wolff \& R. Göbel (Eds.), Digitalisierung: Segen oder Fluch, Wie die Digitalisierung unsere Lebens- und Arbeitswelt verändert (pp. 19-223). Berlin: Springer-Verlag GmbH Deutschland.

Graf, N., Gramß, D., \& Edelkraut, F. (2019). Agiles Lernen: Neue Rollen, Kompetenzen und Methoden im Unternehmenskontext. Freiburg: Haufe-Lexware GmbH \& Co. KG.

Gutbrod, J. (2020). Chancen und Limitierungen der Digitalisierung von Unterricht, Eine Bewertung aus pädagogischer Perspektive. In Karlsruher Institut für Technologie (KIT) \& Institut für Technikfolgenabschätzung und Systemanalyse (ITAS) (Eds.), TATuP-Zeitschrift für Technikfolgenabschätzung in Theorie und Praxis, 29(1), 44-49. oekom verlag GmbH. 
Kerres, M. (2018). Mediendidaktik, Konzeption und Entwicklung digitaler Lernangebote (5. Auflage). Berlin/Boston: Walter de Gruyter GmbH.

Kraft, S. (2003). Blended Learning, Ein Weg zur Integration von E-Learning und Präsenzlernen. In Report - Literatur- und Forschungsreport Weiterbildung, Erfahrungen mit neuen Medien, 26(2), 43-52.

ME310. (2018). Real Companies. Real Projects. Real Design. Retrieved November 19, 2020, from https://web.stanford.edu/group/me310/me310_2018/about.html

mmb Institut. (2019). Lernassistenten und Instant Messaging als neue Lernformen. Retrieved April 30, 2020, from https://www.mmb-institut.de/blog/lernassistenten-undinstant-messaging-als-neuelernformen/

Modlinger, D. (2020). eLearning und Mobile Learning - Konzept und Drehbuch, Handbuch für Medienautoren und Projektleiter (3. Auflage). Wiesbaden: Springer VS.

Poxleitner, E. (2018). Einsatz von Videos für mobiles Lernen. In C. De Witt \& C. Gloerfeld, Handbuch Mobile Learning (pp. 433-456). Wiesbaden: Springer VS.

Redlein, A., Stopajnik, E., Schaad, K., Hofer, S., Höhenberger, C., \& Turnbull, P. (2020). Modern Facility and Workplace Management. Springer Nature Switzerland AG 2020.

Redlein, A., Thrainer, L., \& Lau, C. (2021). Problem-based learning for the teaching of FM skills: Results of a practical use. In The proceedings of the $20^{\text {th }}$ EuroFM Symposium 2021.

Siepmann, F. (2018). eLearning Benchmarking Studie. Teilstudie: Digitale Transformation \& Weiterbildung. Hagen im Bremischen: Siepmann Media and Research.

Springer iversity. (2021). Retrieved January 28, 2021, from https://iversity.org/de/my/courses/online-diy

Stock-Homburg, R., \& Groß, M. (2019). Personalmanagement. Theorien - Konzepte - Instrumente (4. Aufl). Wiesbaden: Springer Gabler.

Weber, A. (2005). Problem-Based Learning. - Ansatz zur Verknüpfung von Theorie und Praxis. Beiträge zur Lehrerinnen- und Lehrerbildung, 23(1), 94-104.

Weber, A. (2007). Problem-Based Learning, Ein Handbuch für die Ausbildung auf der Sekundarstufe II und der Tertiärstufe (2. Auflage). hep Verlag. 